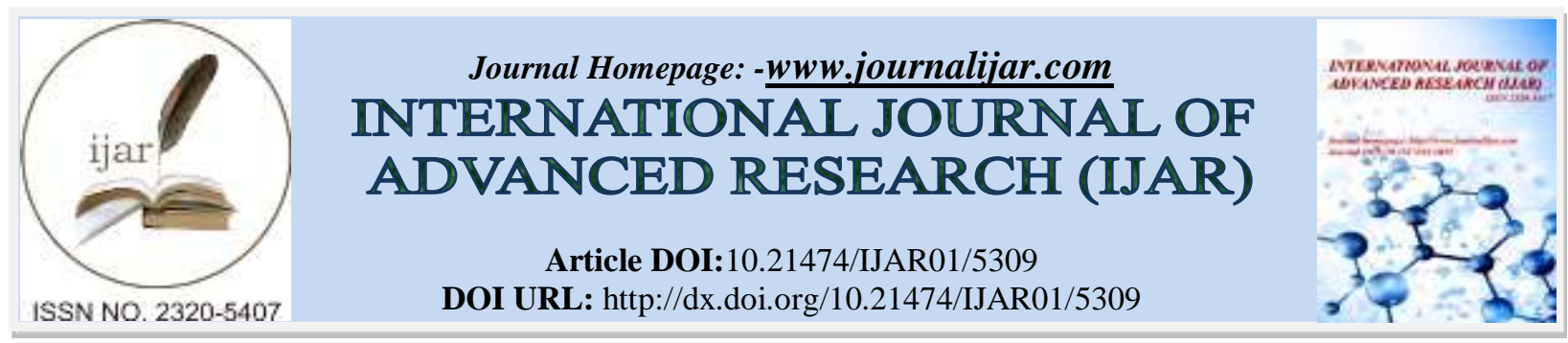

RESEARCH ARTICLE

\title{
CYTOTOXICITY EVALUATION OF BIOACTIVE FRACTION FROM TERMINALIA BELLIRICA(GAERTN.)ROXB. FRUITS IN L929 CELLS.
}

Kuriakose Jayesh, Lal Raisa Helen, A Vysakh, Eldhose Binil and *M. S. Latha. School of Biosciences, Mahatma Gandhi University, Priyadarshini Hills, Kottayam, Kerala, India.

\section{Manuscript Info}

Manuscript History

Received: 02 July 2017

Final Accepted: 04 August 2017

Published: September 2017

Key words:-

Terminaliabellirica; cytotoxicity; L929; MTT assay; LDH leakage assay.

\begin{abstract}
Terminalia bellirica(Gaertn.)Roxb. (Family: Combretaceae) is a well known medicinal plant used in various traditional herbal formulations used to cure several diseases. The dried fruit of Terminalia bellerica has an important place in the traditional Indian system of medicine and forms a major ingredient of several medicaments including "Triphala-" used as general health tonic in Ayurveda. The current study aims to investigate the cytotoxic effect of bioactive ethyl acetate fraction of T.bellirica fruits (EFTB) on L929 cell line. The toxic changes imposed by varying concentrations of the fraction were evaluated by different techniques including MTT, neutral red and LDH leakage assay. The in vitro toxicity studies showed that EFTB, even at its highest concentration of $100 \mu \mathrm{g} / \mathrm{ml}$ used in the study exhibited only mild level of toxicity in L929 cells. The LD50 values of EFTB in all the cytotoxicity assays were found comparatively higher which points to the non- toxic nature of the plant derived bioactive fraction that can be developed into herbal therapeutic agent after further detailed in vivo toxicity studies.
\end{abstract}

Copy Right, IJAR, 2017,. All rights reserved.

\section{Introduction:-}

Traditional systems of medicine like Ayurveda, Unani, Siddha play a vital role in mitigating various ailments of humankind especially those who inhabit rural areas. The demand for plant- based phytotherapeutics is driven by their effectiveness, fewer or no side effects and above all cost effective. In India, out of 45,000 plant species identified with medicinal properties, around twenty thousand medicinal plants are of significant medicinal value and therapeutic potential (Deb et al., 2016). Many of the traditionally used plants have become valuable therapeutics of modern medicine, to list a few digitoxin, opium, morphine, taxol and vincristine.

The herbs possess a rich tradition of use both for nutritional as well as medicinal properties (Kitagishi et al., 2012). In spite of their widespread use and enthusiastic prospects for health promotion, more information is required about the physiological and pharmacological responses to and the molecular targets for specific herbs (Kitagishi et al., 2012). Owing to its increased acceptance across the globe, the plant based medicines need thorough toxicity evaluations before introducing for human consumption. Apart from the general belief that plant based drugs are safe, many of them possess severe toxicity which in turn necessitates thorough toxicity evaluations through in vitro as well as in vivo methods.

Corresponding Author:- M.S. Latha.

Address:-School of Biosciences, Mahatma Gandhi University, Priyadarshini Hills, Kottayam, Kerala, 
Terminalia bellirica (Gaertn.) Roxb. is a medicinal plant which has been traditionally used for various therapeutic purposes(Kuriakose et al., 2017).The fruit of the plant is an essential ingredient of many Ayurvedic formulations such as 'Triphala'(Khare, 2007). In our screening study, aqueous acetone extract of Terminalia bellirica fruits showed maximum antioxidant activity (Jayesh et al., 2016). The aqueous acetone extract of T.bellirica again showed curative potential in $\mathrm{CCl}_{4}$ induced oxidative stress and hepatotoxicity in animal model (Kuriakose et al., 2017). The bioactive ethyl acetate fraction (EFTB) was separated from the aqueous acetone extract and the present study is an attempt to demonstrate in vitro cytotoxicity of EFTB on L929 cell line.

\section{Materials and methods:-}

Chemicals:

All the chemicals used in the study were of high quality analytical grade reagents. Dulbecco's modified Eagles medium, Penicillin, streptomycin and fetal bovine serum were obtained from Gibco Invitrogen (Germany). MTT (3(4,5 dimethylthiazol-2-yl) 2,5diphenyltetrazolium bromide, was purchased from Sigma Aldrich Inc. (St Louis, MO, USA). Tissue culture plates were purchased from Tarson, India. The silica gel (230-400) was purchased from Merck Specialties Pvt.Ltd. (Mumbai, India). All the other chemicals and solvents were used in the study were purchased from Merck Life science Pvt. Ltd. (Mumbai, India).

\section{Plant material:-}

Terminalia bellirica(Gaertn.)Roxb.fruits were procured from Kerala Forest Research Institute, Peechi, India. The specimen sample was deposited at the institute with voucher number SBSBRL 23. After drying the fruits in shade for few days, removed the seeds, finely powdered and stored in airtight container until further use.

\section{Preparation phenolic rich ethyl acetate fraction:-}

Aqueous acetone extract of Terminalia bellirica(Gaertn.)Roxb. fruits was prepared as described earlier (Jayesh et al., 2016) with slight modifications. Briefly, the fruit powder (100 g) was defatted with petroleum ether and then extracted with $70 \%$ aqueous acetone $(300 \mathrm{ml})$ in a mechanical shaker for 72 hours. After three successive extractions, the pooled extracts were filtered through Whatman No.1 filter paper, concentrated to dryness in a rotary evaporator and lyophilized.

The phenolic rich ethyl acetate fraction was prepared by chromatography through a silica gel column (40x1000 mm) with 230-400 meshes. The lyophilized dark powder of Terminalia bellirica fruits was layered on the top of n-hexane equilibrated silica gel column and subjected to fractionation through chromatography. The column was sequentially eluted with $200 \mathrm{ml}$ of n-hexane, dichloromethane, chloroform, ethyl acetate, methanol and water. Similar effluent fractions were pooled on the basis of UV spectral as well as TLC analysis. The ethyl acetate fraction, rich in polyphenols (EFTB) was used for the present study.

\section{Cell culture:-}

The fibroblast (L929) cell line was procured from National Centre for Cell Sciences (NCCS), Pune, India. The cell line was cultured in $25 \mathrm{~cm}^{2}$ tissue culture flask with DMEM supplemented with $10 \%$ heat-inactivated fetal bovine serum (FBS), L-glutamine, sodium bicarbonate and antibiotic solution containing Penicillin (100U/ml), Streptomycin $(100 \mu \mathrm{g} / \mathrm{ml})$ and Amphoteracin B $(2.5 \mu \mathrm{g} / \mathrm{ml})$ at $37^{\circ} \mathrm{C}$ in a humidified $5 \% \mathrm{CO}_{2}$ incubator (NBS Eppendorf, Germany). The viability of the cultured cell line was evaluated by direct observation through Inverted phase contrast microscope as well as by trypan blue dye exclusion method.

\section{Morphological evaluation of cytotoxicity:-}

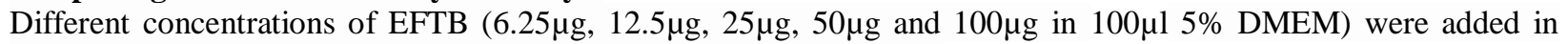
triplicates to the respective wells in the 96 well plates seeded with $100 \mu 1$ suspension in $10 \%$ growth medium of fibroblast L929 cells at a density of $5 \times 10^{4}$ cells/well and incubated at $37^{\circ} \mathrm{C}$ in a humidified $5 \% \mathrm{CO}_{2}$ incubator for 48 hours.

Following the incubation period, the plates were observed in an inverted phase contrast microscope (Olympus CKX41 with Optika Pro5 CCD camera) for any detectable indications of cytotoxicity such as rounding or shrinking of cells, granulation and vacuolization in the cytoplasm of the cells and microscopic observations were recorded as images. 


\section{MTT Cell viability assay:-}

Analysis of cell viability was performed by MTT assay in L929 cell line according to the previously described method(Mosmann, 1983). The assay is based on the cleavage of the yellow tetrazolium salt, 3-(4-5- dimethylthiozol2-yl) 2-5- diphenyl-tetrazolium bromide (MTT) into purple formazan by metabolically active cells, which can be photometrically quantified. An increase in the number of living cells results in an increase in total metabolic activity, which leads to a stronger color formation.

The cultured confluent monolayer of cells were harvested by trypsinization ( $0.5 \%$ trypsin/2.6mM EDTA), washed with phosphate buffered solution (PBS) and suspended in $10 \%$ growth medium. Cell counting and cell viability were performed by trypan blue technique. The cell suspension $(100 \mu 1)$ was seeded into the 96 well tissue culture plate at a density of $5 \times 10^{4}$ cells/well and incubated at $37^{\circ} \mathrm{C}$ in a humidified $5 \% \mathrm{CO}_{2}$ incubator. After attaining sufficient growth in the cell line (L929), the growth medium was removed, varying concentrations of EFTB $(6.25 \mu \mathrm{g}, 12.5 \mu \mathrm{g}$, $25 \mu \mathrm{g}, 50 \mu \mathrm{g}$ and $100 \mu \mathrm{g}$ ) in 5\% DMEM was added in triplicates to the respective wells and incubated at $37^{\circ} \mathrm{C}$ in a humidified $5 \% \mathrm{CO}_{2}$ incubator for 48 hours.

The media of the cultured cell lines were removed after the incubation period, attaining proper confluent growth, culture media were removed and replaced with fresh media containing $30^{\circ} \mathrm{C}$ of reconstituted MTT $(0.5 \mathrm{mg} / \mathrm{ml})$ solution and incubated for 4 hours at $37^{\circ} \mathrm{C}$. The formazan crystals formed were dissolved by the $100 \mu 1$ of DMSO added into the wells and optical density was measured using microplate reader at $570 \mathrm{~nm}$.

The percentage cell viability was calculated using the formula:

$$
\text { Percentage cell viability }=(\text { sample OD/control OD }) \times 100
$$

The LD50 value of the cell line was determined from the linear equation obtained from the plot between the percentages of cell viability at different concentrations of EFTB.

\section{Neutral red cell viability assay:-}

The viability assay by neutral red uptake enables quantitative estimation of viable cells in a culture which is based on the capacity to integrate the dye within the lysosome of living cells. The assay performed was based on the procedures described by Borenfreund \& Puerner and Repetto et.al (Borenfreund and Puerner, 1985; Repetto et al., 2008). The cultured monolayer of L929 cells in 96 -well tissue culture plates were treated with varying concentrations of $\operatorname{EFTB}(6.25 \mu \mathrm{g}, 12.5 \mu \mathrm{g}, 25 \mu \mathrm{g}, 50 \mu \mathrm{g}$ and $100 \mu \mathrm{g})$ and incubated at $37^{\circ} \mathrm{C}$ in a humidified $5 \% \mathrm{CO}_{2}$ incubator for 48 hours. The neutral red solution $(100 \mu \mathrm{l})$ in serum free medium was added into each wells of the culture plate and incubated for 3 hours at $37^{\circ} \mathrm{C}$ in a humidified $5 \% \mathrm{CO}_{2}$ incubator. After decanting the medium and thorough washing with PBS, the dye was extracted from each well by treating with $200 \mu 1$ of $50 \%$ ethanol containing $1 \%$ acetic acid. The plate was kept at room temperature for 20 minutes with gentle shaking at intervals after which resulting solutions from each wells were transferred to fresh 96 -well plate and absorbance at 540nm was recorded using the microplate reader (Spectra max190-Molecular Devices). The OD value is directly proportional to the number of viable cells and the percentage cell viability was calculated using the formula:

Percentage cell viability $=($ sample OD/control OD $) \times 100$

\section{Lactate dehydrogenase assay:-}

The assay is based on the conversion of lactate to pyruvate in the presence of LDH with simultaneous reduction of NAD to NADH which results in a change of OD to be measured at $340 \mathrm{~nm}$. The cytotoxicity induced by EFTB was determined by the quantitative estimation of cytoplasmic lactate dehydrogenase (LDH) leaked into the culture medium by the method of Renner et al., 2003(Renner et al., 2003). Briefly, after the exposure of cell lines to the different concentrations of EFTB, the culture medium was aspirated and centrifuged at $4000 \mathrm{rpm}$ for $10 \mathrm{~min}$ to get cell free supernatant. The supernatant $(100 \mu \mathrm{l})$ was mixed with $0.1 \mathrm{ml}$ of potassium phosphate buffer $(0.1 \mathrm{M})$, NADH $(6 \mathrm{mM})$ and sodium pyruvate solution $(10 \mathrm{mM})$ and the reduction in optical density was measured at $340 \mathrm{~nm}$. The percentage of cell viability was calculated using the formula:

Percentage cell viability $=($ sample OD/control OD $) \times 100$

Statistical analysis:-

All experiments were carried out in triplicates and the data was reported as mean \pm SD. GraphPad Prism@ version 5.03 for Windows (GraphPad Software, USA) was used for all statistical analysis. The LD50 values were calculated 
by regression analysis using the software. The data was statistically analyzed either by one-way ANOVA and the values with $\mathrm{p} \leq 0.05$ were considered as significant.

\section{Results:-}

Morphological evaluation of cytotoxicity:-

The detectable toxic changes, such as rounding or shrinking, granulation and vacuolization in the cytoplasm, after EFTB treatment in L929 cells were recorded as photographs after thorough microscopic observations. The plant fraction produced mild to medium level of toxicity in the cell line at its higher concentrations (Figure: 1).
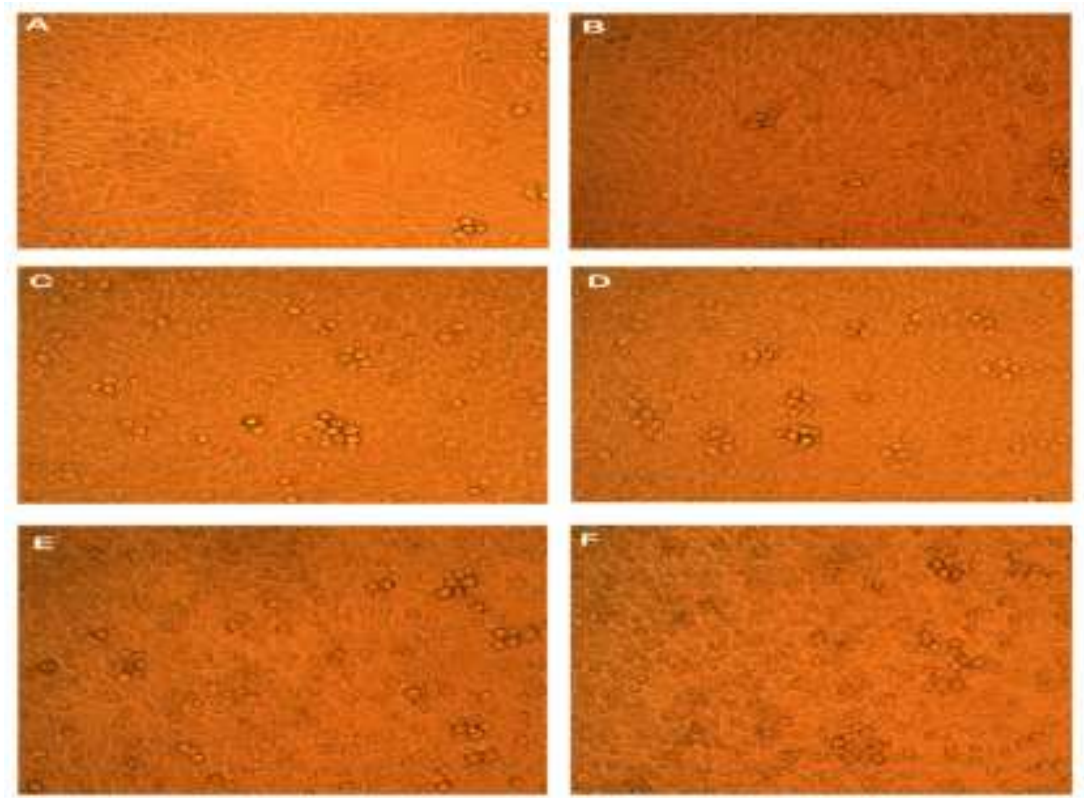

Figure:- 1 Morphological changes of L929 cells

\section{MTT cell viability assay:-}

The cell viability of L929 cells after treating with different concentrations of EFTB was evaluated using the MTT assay and the result was represented as percentage of viability (Figure: 2). The EFTB exhibited an LD50 of 1346.00 $\pm 50.27 \mu \mathrm{g} / \mathrm{ml}$ in the MTT cell viability assay (Table:1)

Figure: - 2 MTT Assay

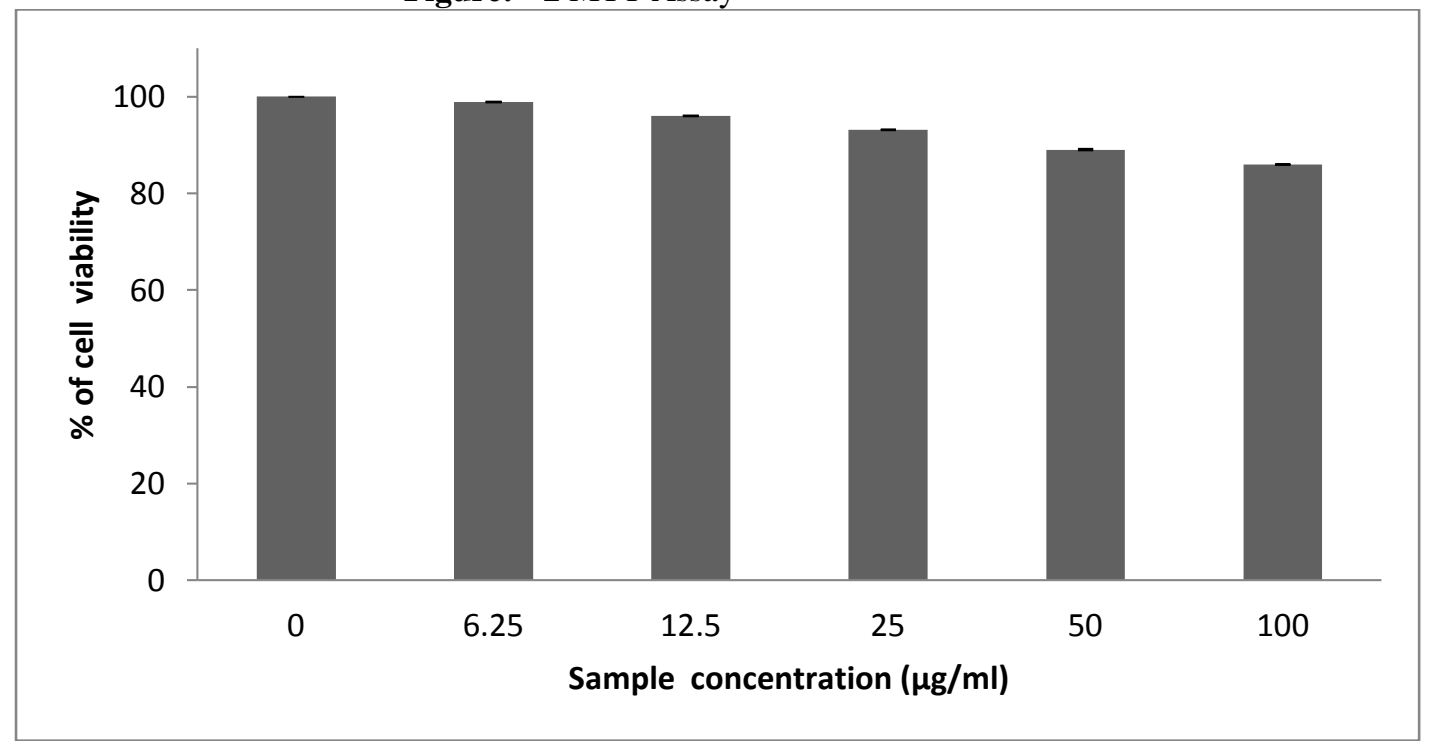


Table 1:-LD50 values of EFTB in L929 cells

\begin{tabular}{|l|l|}
\hline Assay & LD50 $(\mu \mathrm{g} / \mathrm{ml})$ \\
\hline MTT assay & $1346.00 \pm 50.27$ \\
\hline Neutral red staining & $1316.67 \pm 36.77$ \\
\hline LDH leakage assay & $1087.67 \pm 78.01$ \\
\hline
\end{tabular}

Effect of EFTB on neutral red viability assay:-

The percentage of viability observed after treating L929 cells with the highest concentration of EFTB (100 $\mu \mathrm{g} / \mu \mathrm{l})$ was $85.89 \pm 0.05$ (Figure: 3 ) and the concentration of EFTB that produced $50 \%$ cell death (LD50) was estimated at $1316.67 \pm 36.77 \mu \mathrm{g} / \mu \mathrm{l}$

Figure 3:-Neutral red assay

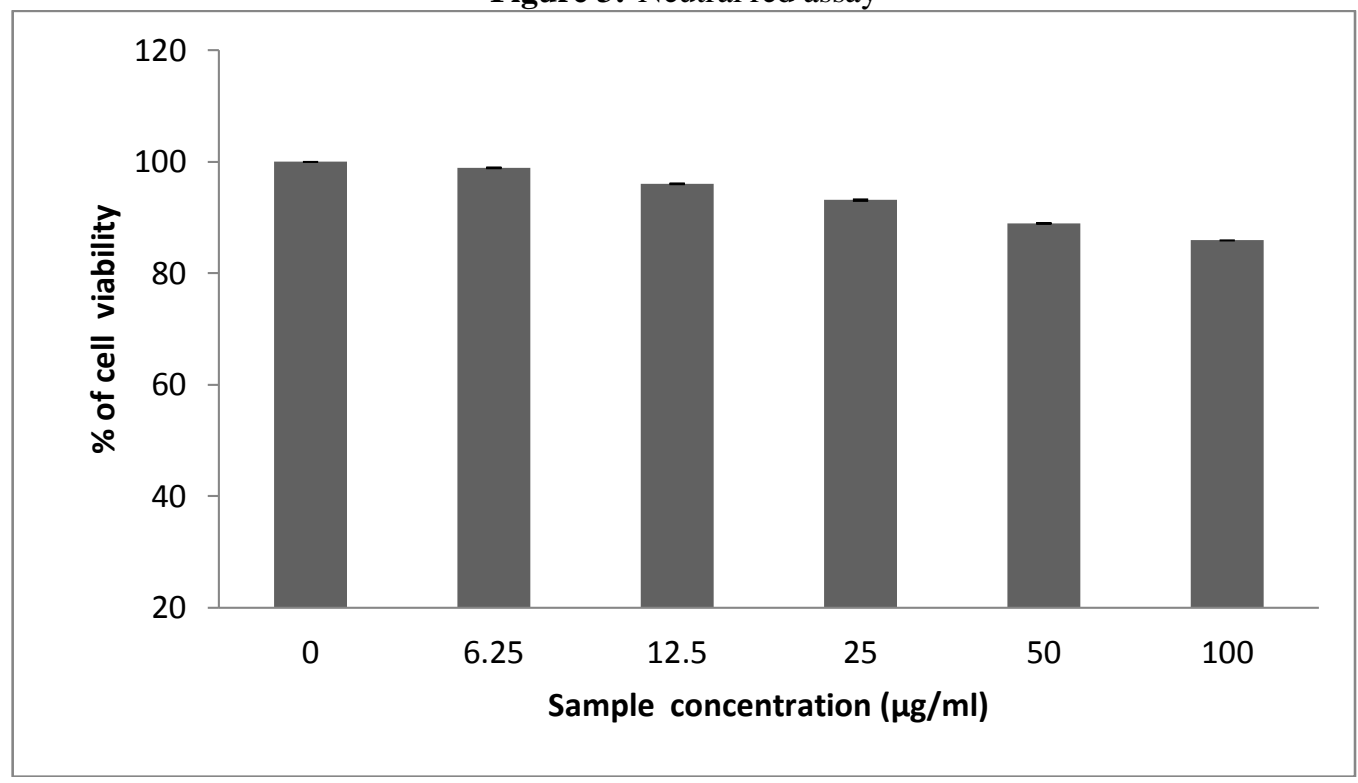

\section{LDH assay:-}

LDH leakage assay showed that EFTB treatment produced mild toxic effects in the L929 cells with an LD50 value of $1087.67 \pm 78.01 \mu \mathrm{g} / \mu \mathrm{l}$ (Table: 3 ) and observed a viability percentage of $84.91 \pm 0.03$ at $100 \mu \mathrm{g} / \mathrm{ml}$ of the plant fraction (Figure: 3 ).

Figure 4:-LDH leakage assay

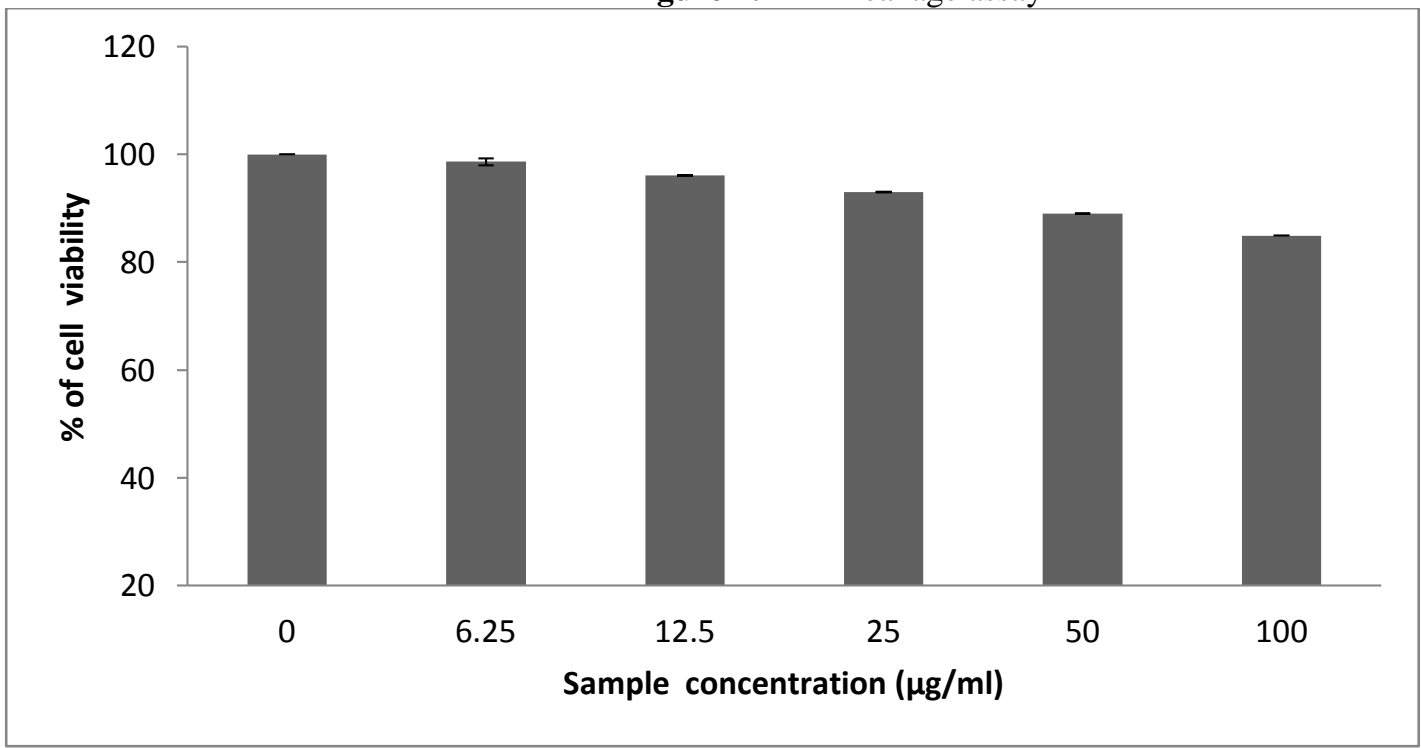




\section{Discussion:-}

Plants have become an important source of nutrition as well as 'alternative medicine' and the demand of plant-based drugs is on the expansion nowadays as they are associated with fewer side effects and cost effective(Helen et al., 2017). India has a rich tradition of the plant-based medicinal system of treating various diseases and very often, bioactive molecules from medicinal plants act synergistically to produce larger physiological benefits in human beings than the individual effects of each component(Jayesh et al., 2017). Ayurveda, being one of the oldest healthcare systems that evolved in the Indian subcontinent largely make use of the medicinal properties of traditional plants for mitigating various human sufferings (Jayesh et al., 2017). Herbal remedies, even though they have become more popular in the perception of harmless owing to their natural origin, they too possess adverse effects(Ernst et al., 1998).

Terminalia bellirica(Gaertn.)Roxb. (Combretaceae), known as Bastard Myrobalan is a large deciduous tree found throughout India up to an elevation of 900 meters(C.P.Khare, 2007). Apart from being an integral part in 'Triphala', the fruits are widely used in various traditional therapeutic formulations in the indigenous system of medicine either alone or in combination with other plant based drugs(Khare, 2007). The previous studies on Terminalia bellirica fruits have shown that aqueous acetone extract possesses in vitro antioxidant and in vivo hepatoprotective activity (Jayesh et al., 2016; Kuriakose et al., 2017).The extract did not produce any toxicity in animal models (Jayesh et al., 2017). The bioactive polyphenol rich ethyl acetate fraction (EFTB) of Terminalia bellirica fruits was separated through bioassay guided approach. It is much essential for the herbal formulations to have scientific toxicological safety assessment before being developed into a new herbal therapeutic medicament (Jayesh et al., 2017). So, the present study is aimed to assess the toxic effects of EFTB on L929 cell line.

The toxic effects of EFTB on L929 was evaluated by various techniques such as MTT, neutral red assay, LDH leakage assay in addition to the morphological observations of any detectable toxic changes such as rounding or shrinking, granulation and vacuolization in the cytoplasm in the cell line. The LDH leakage assay is based on the release of the enzyme into the culture medium after the cell membrane damage whereas the MTT assay is mainly based on the enzymatic conversion of MTT in the mitochondria of live cells. The neutral red assay is a colorimetric assay measuring the uptake of the dye by functional lysosomes (Fotakis and Timbrell, 2006). The reliability of the MTT assay was tested for its validity in various cell lines(Mosmann, 1983). The neutral red assay which is used to measure cell viability has been used as an indicator of cytotoxicity in cultures of primary hepatocytes (Fautz et al., 1991) and other cell lines(Morgan et al., 1991).

All the assays employed in the study clearly demonstrated the non toxic nature of EFTB which is evident from the insignificant level of cell death even at the highest concentration of the plant derived fraction. Hence, the poly phenol rich EFTB is safe for developing into a therapeutic herbal formulation with various pharmacological properties.

\section{Conclusion:-}

The phenolic rich bioactive fraction of Terminalia bellirica fruits was analyzed for possible toxic effects in L929 cells using different assays of cytotoxicity. Cytotoxic effect of the fraction was assessed by MTT, neutral red and LDH leakage assays. These assays have shown that EFTB does not impose any toxic effects in the cell line. The outcome of the in vitro cytotoxicity studies suggests developing a therapeutic herbal formulation containing EFTB, after necessary in vivo toxicity evaluations.

\section{Acknowledgement:-}

The authors are grateful to School of Biosciences, Mahatma Gandhi University and Biogenix Research Center, Poojapura, Thiruvananthapuram, India for providing the excellent research support. J.K gratefully acknowledges UGC for providing teacher fellowship under the UGC-FDP scheme.

\section{Conflict of interest:-}

The authors declare that they have no conflict of interest. 


\section{References:-}

1. Borenfreund, E., Puerner, J.A., 1985. Toxicity determined in vitro by morphological alterations and neutral red absorption. Toxicol. Lett. 24, 119-124. doi:10.1016/0378-4274(85)90046-3

2. C.P.Khare, 2007. Indian Medicinal Plants An illustrated Dictionary. Springer(India) Private Limited.

3. Deb, A., Barua, S., Das, B., 2016. Pharmacological activities of Baheda (Terminalia bellerica): A review. Jpp 5, 194-197.

4. Ernst, E., Anderson, L., Phillipson, J., al., et, Weidenhammeer, W., Melchart, D., 1998. Harmless Herbs? A Review of the Recent Literature. Am. J. Med. 104, 170-178. doi:10.1016/S0002-9343(97)00397-5

5. Fautz, R., Husein, B., Hechenberger, C., 1991. Application of the neutral red assay (NR assay) to monolayer cultures of primary hepatocytes: rapid colorimetric viability determination for the unscheduled DNA synthesis test (UDS). Mutat. Res. Mutagen. Relat. Subj. 253, 173-179. doi:10.1016/0165-1161(91)90130-Z

6. Fotakis, G., Timbrell, J.A., 2006. In vitro cytotoxicity assays: Comparison of LDH, neutral red, MTT and protein assay in hepatoma cell lines following exposure to cadmium chloride. Toxicol. Lett. 160, $171-177$. doi:10.1016/j.toxlet.2005.07.001

7. Helen, L.R., Jayesh, K., Latha, M.S., 2017. Safety assessment of aqueous acetone extract of Clerodendrum infortunatum L. in Wistar rats. Comp. Clin. Path. 26, 369-375. doi:10.1007/s00580-016-2383-1

8. Jayesh, K., Helen, L.R., Binil, E., Latha, M., Latha, M.S., 2016. Comparative Antioxidant Properties of Terminalia bellirica www.ijppr.humanjournals.com. Ijppr.Human 7, 310-320.

9. Jayesh, K., Helen, L.R., Vysakh, A., Binil, E., Latha, M.S., 2017. In vivo toxicity evaluation of aqueous acetone extract of Terminalia bellirica (Gaertn.) Roxb. fruit. Regul. Toxicol. Pharmacol. 86, 349-355. doi:10.1016/j.yrtph.2017.04.002

10. Khare, C.P., 2007. Indian Medicinal Plants. Springer New York, New York, NY. doi:10.1007/978-0-38770638-2

11. Kitagishi, Y., Kobayashi, M., Matsuda, S., 2012. Protection against cancer with medicinal herbs via activation of tumor suppressor. J. Oncol. 2012. doi:10.1155/2012/236530

12. Kuriakose, J., Lal Raisa, H., Vysakh, A., Eldhose, B., Latha, M.S., 2017. Terminalia bellirica (Gaertn.) Roxb. fruit mitigates $\mathrm{CCl} 4$ induced oxidative stress and hepatotoxicity in rats. Biomed. Pharmacother. 93, $327-333$. doi:10.1016/j.biopha.2017.06.080

13. Morgan, C.D., Mills, K.C., Lefkowitz, D.L., Lefkowitz, S.S., 1991. An improved colorimetric assay for tumor necrosis factor using WEHI 164 cells cultured on novel microtiter plates. J. Immunol. Methods 145, $259-62$.

14. Mosmann, T., 1983. Rapid colorimetric assay for cellular growth and survival: Application to proliferation and cytotoxicity assays. J. Immunol. Methods 65, 55-63. doi:10.1016/0022-1759(83)90303-4

15. Renner, K., Amberger, A., Konwalinka, G., Kofler, R., 2003. Changes of mitochondrial respiration, mitochondrial content and cell size after induction of apoptosis in leukemia cells. Biophys. Acta (BBA ....

16. Repetto, G., del Peso, A., Zurita, J.L., 2008. Neutral red uptake assay for the estimation of cell viability/cytotoxicity. Nat. Protoc. 3, 1125-31. doi:10.1038/nprot.2008.75 